COMPETITOR: Jurnal Pendidikan Kepelatihan Olahraga

Volume 13 Number 1 Year 2021

e-ISSN: 2657-0734 \& p-ISSN: 2085-5389

This work is licensed under a Creative Commons Attribution 4.0 International License

\title{
Differences Learning Outcomes At The Forehand Groundstrokes Beginner Athletes
}

\author{
Dian Pujianto \\ Program Study of Physical Education / Faculty of Teacher Training and Education / \\ Bengkulu University / Bengkulu / Indonesia \\ J1. WR. Supratman, Kandang Limun, Kec. Muara Bangka Hulu, Sumatera, Bengkulu, KP.38371 \\ dianpujianto@unib.ac.id
}

Received: January 26, 2021; Reviewed: February 13, 2021; Accepted: February 22, 2021;

Published: February 28, 2021

\begin{abstract}
The purpose of this study was to determine the differences in the results of learning the skills of groundstrokes forehand tennis in novice athletes by using two different forms of learning media, namely demonstration media and video media. This research is an experimental research which was conducted in the city of Bengkulu in the province of Bengkulu in 2016. The population of this study was the 5th semester students who were new to tennis court, amounting to 20 students. The research sample used a total sample, the sample was divided into two groups, the first group used demonstration media and the second group used video media. Data were collected through tests and measurements of the skills of tennis groundstrokes. The results of data analysis with the t test with the SPSS 21 program show a coefficient of 0.048 , this price is smaller than the coefficient of 0.05 , so from this comparison it can be concluded that there is a difference in learning outcomes of tennis forehand grounstroke skills using demonstration media with media. video.
\end{abstract}

Keywords: Learning Media; Groundstroke; Forehand.

\section{INTRODUCTION}

The Covid-19 pandemic has hit the world, starting from Wuhan China at the end of 2019 and entering Indonesia in March 2020. The Covid-19 pandemic has changed the order of life both from a social, economic and educational perspective (Chaturvedi et al., 2021). The economic impact can be seen clearly with the number of community economies that have collapsed due to limited community activities. Likewise in the world of education, teaching and learning activities that are usually carried out face-toface have turned into networks, and of course this changes the learning system drastically for both teachers, students and for parents. Learning through networks is carried out at the pre-school, elementary, secondary and tertiary levels.

Problems arise when learning requires practicum. Practical learning, such as 
Differences Learning Outcomes At the forehand groundstrokes Beginner Athletes

physical education learning, is not optimal in the learning process. This difficulty also occurs at the college level. Practicum lectures are not running optimally. One of the practicum courses affected by the Covid 19 pandemic is a tennis course. Field tennis is included in the compulsory course because it has been considered as a sport that is able to get someone to socialize more socially economically, apart from being included in the compulsory course, tennis is also given a forum in the tennis field student activity unit. Learning tennis court takes longer, because tennis skills are more complex.

Based on previous lecture experiences, many students have difficulty learning tennis, because for students, tennis is a new skill for them. Learning tennis court has used the demonstration method from the teaching team and then students practice it, but with the emergence of the Covid 19 pandemic, face-to-face lectures are classically prohibited, this clearly has an impact on student learning outcomes. The uncertain development of the Covid 19 pandemic in Indonesia has resulted in Government policies being less supportive of the world of education (Djalante et al., 2020). Tennis requires coordination of both eyes and hands as well as eyes and feet. (Siedentop, 1994) states "coordination is the ability to use body parts to perform motor skill smoothly and accurately". This statement explains that coordination is the ability to use body parts to display movement skills in a smooth and accurate manner. The ability to use two parts of the body simultaneously, such as when catching a ball, there are two parts of the body that move together, namely the eye when facing the object to be caught and the hand that captures the object.

Difficulty learning tennis court also occurs in students of the physical education study program at the University of Bengkulu. Learning is an ongoing process. Learning is a permanent result which results from practice and experience. (Wingkel, 2017) argues that learning is a mental process or activity that cannot be witnessed from the outside. Likewise learning the skills of tennis groundstrokes. According to (Brown, 2015) groundstrokes are strokes after the ball bounces onto the field, meaning groundstrokes can be interpreted as a shot made after the ball hits the ground. To perform this movement the athlete must have coordination. To be able to learn well requires learning media.

Media is any person, material, tool, or event that can create a condition capable of providing input to learners to receive knowledge, skills, and attitudes (Samsudin, 2014). (Kolhar et al., 2021) states that the media is the plural form of the medium (intermediary), as a means of communication, the media are classified into six categories, namely; text, 
Differences Learning Outcomes At the forehand groundstrokes Beginner Athletes

audio, visual, video, modification, and human. Then learning is a process of student learning provided by educators and has learning basic words. Learning is a change that is relatively permanent and occurs either directly or indirectly as a result after the learning process is complete (Munz et al., 2021). (Corbett \& Spinello, 2020) states "learning: a change in the capability of a person to perform a skill that must be inferred from a relatively permanent improvement in performance as a result of practice or experience".

The learning process in the Covid 19 pandemic was carried out online (Mishra et al., 2020), and of course this affects the learning media used. In the Covid 19 pandemic the media used used tutorials from YouTube or instructional videos made by teachers (Cho \& Hong, 2021). The online media used are video content sent via e-learning and Whatapps messages (Sukendro et al., 2020), the use of these two electronic message media is considered effective, because all students already have the necessary equipment. The existence of changes in the learning process has indirectly resulted in changing the curriculum in education, this curriculum change can be effective if all learning components are ready (Seah et al., 2021). However, the effectiveness of online learning, especially in practicum courses, has not been tested for its effectiveness. Especially in the tennis court course, which requires a habit of hitting the ball continuously, by seeing clear examples such as the use of demonstration media. Based on the description above, it is necessary to test the use of learning media to improve tennis learning outcomes, which is appropriate for the practicum course, namely tennis court in the physical education study program. Demonstration learning media and video tutorials for basic tennis court techniques.

\section{METHOD}

The research approach used is experimental research with a comparative experimental design, which is to compare the learning outcomes of two groups (Ali Maksum, 2012), the group treated with demonstration media and the group given the need for tennis tutorial video media. The population of this study were 20 students of the physical education study program. The sample used was total sampling, with 10 students in the demonstration media group and 10 students in the video group. The use of small samples was due to the treatment procedure using the Covid 19 health protocol. The data collection technique used the tennis groundstroke forehand skills test, the instrument used the Dyer groundstroke forehand test. The data analysis technique used the $t$ test with the help of SPSS 21. 
Differences Learning Outcomes At the forehand groundstrokes Beginner Athletes

\section{RESULTS AND DISCUSSION}

Based on the results of the final test for tennis groundstroke forehand skills in a group of students using demonstration media, the following data were obtained:

Table 1.

The results of data on students' groundstroke forehand skills using demonstration learning media

\begin{tabular}{cccc}
\hline No & Interval Class & Frequeny & Persentasi (\%) \\
\hline 1 & $13-14,5$ & 1 & 10 \\
2 & $15-16,5$ & 1 & 10 \\
3 & $17-18,5$ & 2 & 20 \\
4 & $19-20,5$ & 4 & 40 \\
5 & $21-22,5$ & 2 & 20 \\
\hline & Amount & $\mathbf{1 0}$ & $\mathbf{1 0 0}$ \\
\hline
\end{tabular}

Based on Table 1, students who have groundstroke forehand skills on average and above the average are 8 (eight) $80 \%$ of students, and for students who have groundstroke forehand skills below the average there are 2 (two) $20 \%$. From the existing data, it can be illustrated that the skills of students who are trained using demonstration learning media have a satisfactory level of skill when compared with the learning outcomes in lectures before the existence of this study. For more details about this data description will be presented in the following histogram image.

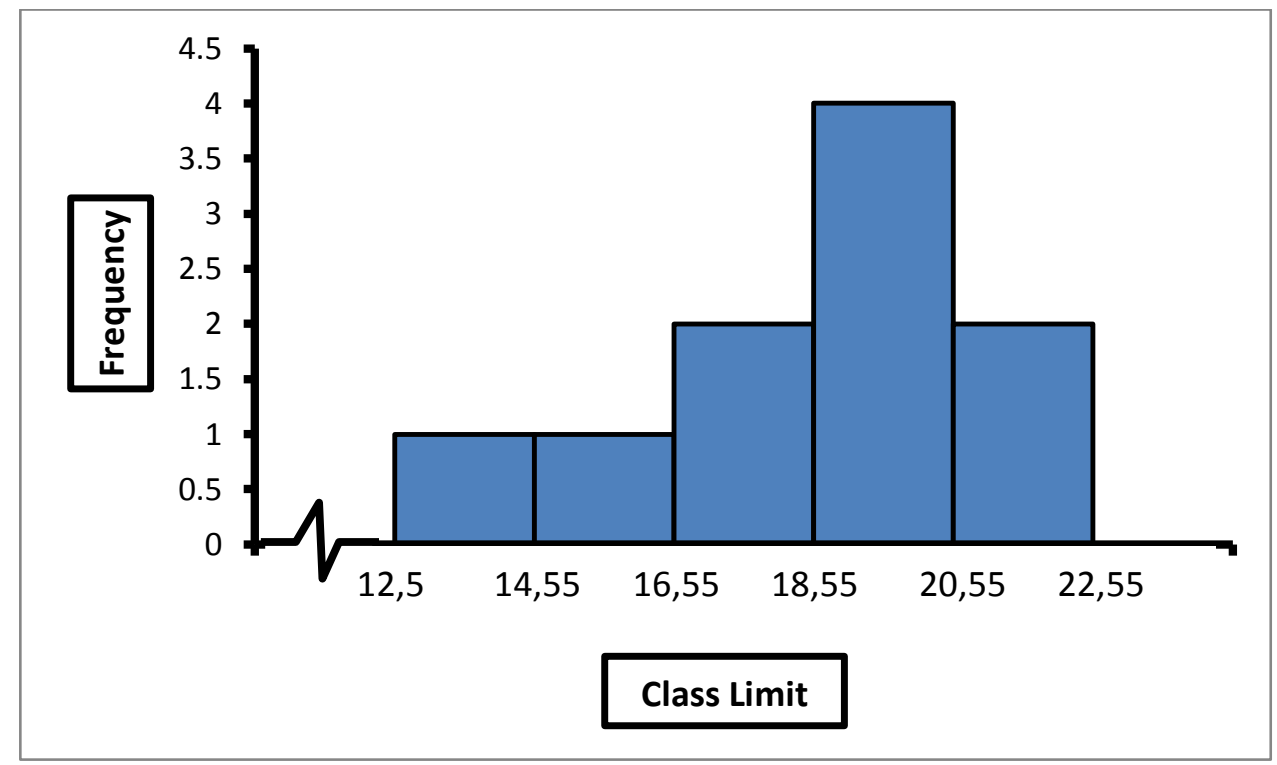

Ficture 1.

Histogram scores for students' groundstroke forehand skills using demonstration learning media 
Differences Learning Outcomes At the forehand groundstrokes Beginner Athletes

The following is data on groundstroke forehand skills of students learning to use video media:

Table 2.

The results of the data for students' groundstroke forehand skills using video learning media

\begin{tabular}{cccc}
\hline No & Interval Class & Frequeny & Persentasi (\%) \\
\hline 1 & $11-12,5$ & 1 & 10 \\
2 & $13-14,5$ & 4 & 40 \\
3 & $15-16,5$ & 2 & 20 \\
4 & $17-18,5$ & 2 & 20 \\
5 & $19-20,5$ & 1 & 10 \\
\hline & Amount & $\mathbf{1 0}$ & $\mathbf{1 0 0}$ \\
\hline
\end{tabular}

Based on Table 2 it can be illustrated that students in the treatment group with video learning media have the following score; 1 (one) $10 \%$ of students have a score between $11-12.5,4$ (four) $40 \%$ of students have a score of $13-14.5,2$ (two) $20 \%$ of students have a score of $15-16.5,2$ (two) $20 \%$ of students have a score of $17-18.5$, and 1 (one) $10 \%$ of students have a score of 19 - 20.5. Based on this data, students who have groundstroke forehand skills on average and above average are 5 (five) $50 \%$ of students, and for students who have groundstroke forehand skills below the average there are 5 (five) $50 \%$. For more details about this data description will be presented in the following histogram image.

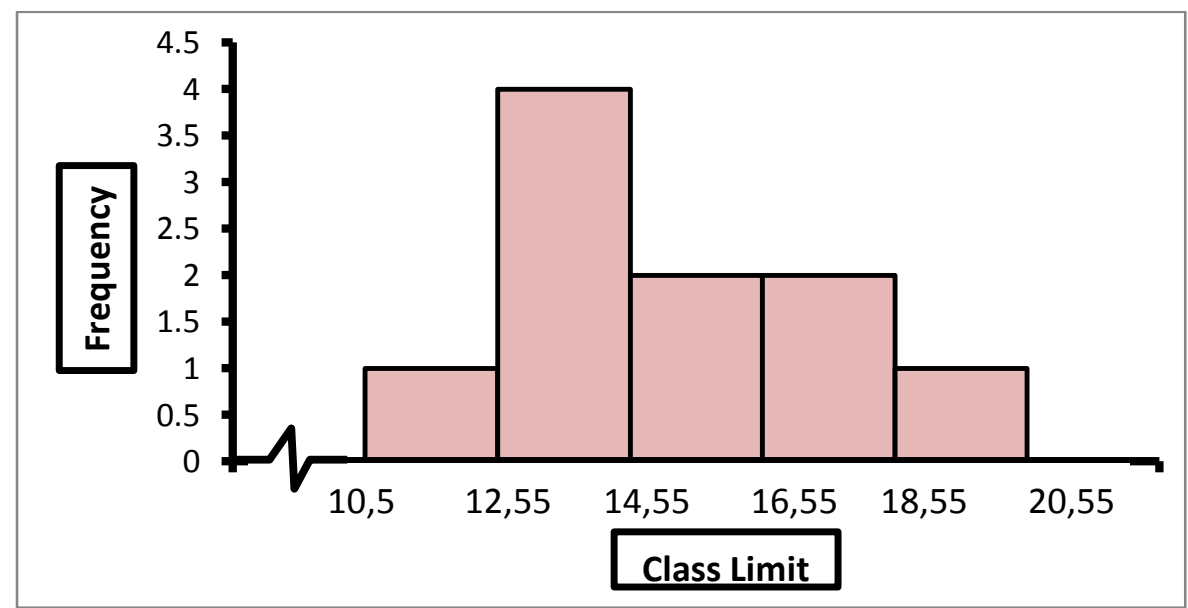

Ficture 2.

Histogram scores for students' groundstroke forehand skills using video learning media

The research results that have been described in Table 1 and Table 2 show different results, but to ensure there is a real difference or there is no need for statistical testing, 
Differences Learning Outcomes At the forehand groundstrokes Beginner Athletes

before statistical testing or hypothesis testing requires testing the analysis prerequisites. The following are the results of the analysis prerequisite test, the normality test of the data from the demonstration learning media group and the video learning media group:

Table 3.

Normality Test Results forehand groundstrokes Data

\begin{tabular}{lccccccr}
\hline & \multicolumn{2}{c}{ Kolmogorov-Smirnov $^{\mathbf{a}}$} & \multicolumn{3}{c}{ Shapiro-Wilk } \\
& Statistic & df & Sig. & Statistic & df & Sig. \\
\hline Media & .164 & 10 & .167 & .972 & 10 & .795 \\
Demonstrasi & & & & & & & \\
Media Video & .185 & 10 & .071 & .911 & 10 & .067 \\
\hline
\end{tabular}

Based on Table 3 above, the data condition can be described. In the demonstration learning media group, the analysis results were obtained with a coefficient of 0.167 in the Kolmogorov-Smirnov test table, this coefficient was then compared with a significance level of 0.05 . If the correlation coefficient is greater than the significance level of 0.05 , the data is not significant, then this means that the data comes from a normally distributed population. In the video learning media group, a coefficient of 0.71 was obtained. This coefficient is greater than the significance level of 0.05 so that the data in the video learning media group comes from a normally distributed population. Further testing the prerequisite analysis of variance homogeneity, here are the data;

Table 4.

Result of Forehand Groundstroke Variant Homogeneity Test

\begin{tabular}{cccc}
$\mathbf{F}$ & $\mathbf{d f 1}$ & $\mathbf{d f 2}$ & Sig. \\
\hline 0.425 & 2 & 19 & 0.829
\end{tabular}

Based on Table 4. above, the data condition can be described. In the groundstroke forehand skill group, the analysis results obtained with a coefficient of 0.829 in the Levene's Test of Equality of Error Variances table, this coefficient is then compared with a significance level of 0.05 . If the correlation coefficient is greater than the significance level of 0.05 , the data is not significant, then this means that the data comes from a homogeneous population. The data is in normal and homogeneous conditions, then the data will be tested whether in different conditions or not by using the $t$ test. The following are the results of the $t$ test with the help of SPSS 21 software; 
Differences Learning Outcomes At the forehand groundstrokes Beginner Athletes

Table 5.

T Test Results for Forehand Groundstroke Skills

\begin{tabular}{|c|c|c|c|c|c|c|}
\hline \multirow[b]{2}{*}{ KLMPK } & \multirow[b]{2}{*}{ KLMPK } & \multirow{2}{*}{$\begin{array}{c}\text { Mean } \\
\text { Difference (I-J) }\end{array}$} & \multirow[b]{2}{*}{ Std. Error } & \multirow[b]{2}{*}{ Sig. } & \multicolumn{2}{|c|}{ 95\% Confidence Interval } \\
\hline & & & & & Lower Bound & Upper Bound \\
\hline $\begin{array}{l}\text { Demonstration } \\
\text { Media }\end{array}$ & Media Video & $3.30000^{*}$ & 1.06654 & .035 & .1489 & 6.4511 \\
\hline
\end{tabular}

Based on the $t$ test in Table 5 between groups of demonstration media and video media, the coefficient value is 0.035 . This price is smaller than the significance price of 0.05. So from this comparison it can be concluded that reject $\mathrm{H}_{0}$ and accept $\mathrm{H}_{1}$. Thus there are differences in the use of demonstration learning media with video learning media on students' groundstroke forehand skills. This fact states that the use of appropriate learning media can have a positive influence on the learning process and learning outcomes. The high coordination ability of students is a dominant factor in the mastery of new motion learning (Dian Pujianto, Asmawi, James Tangkudung, 2015). In this group of students it will be easier to learn new movement skills with the use of the right media (Gatica-Rojas et al., 2017). This is evidenced in this study, students who were taught the skills of forehand groundstroke by using demonstration learning media they were able to see firsthand the process of the movement of the tennis forehand groundstroke strokes, as soon as they saw them immediately practice these movements so that the learning by doing process occurred.

Through this direct experience students can absorb all available information through their various senses so that information is more perfectly stored in the student's short term memory system (Đorđić et al., 2016). When information is stored properly, it will be easy to remember so that it is easy to describe it in a real action, especially if it is supported by good coordination skills (Elena et al., 2014). So that in the process of mastery of motion it will be easier and better (Dian Pujianto et.al, 2020). From the results of hypothesis testing, it turns out that there is a significant difference in the mean price of the two groups, this is evidenced by the results of statistical calculations described in the above section.

The description above states that there are significant differences between the two groups. Differences in learning outcomes through instructional media on tennis forehand groundstroke skills. In general, video media is good at improving cognitive abilities but in improving other aspects it has not been studied in detail (Meyer et al., 2019). Based on this fact, the selection of learning media in the learning and training process must be the 
Differences Learning Outcomes At the forehand groundstrokes Beginner Athletes

basis for consideration of a teacher and trainer, in addition to the selection of learning media, a teacher and trainer must also pay attention to the initial conditions of students and trainees. Knowledge of the initial conditions of these students will provide input to choose learning media that can accommodate all students who have different characteristics.

\section{CONCLUSIONS AND SUGGESTIONS}

Based on the results of hypothesis testing, it can be concluded that there is a significant difference between the learning outcomes of students using groundstroke forehand using demonstration media and students using video media. The learning outcomes of students using demonstration media were higher than those of students who used video media. In fact, movement skills must be taught directly to students so that students can get good learning outcomes. The results of this study are still limited to a small sample, so that a broader study is needed, and several important variables in the learning process have not run optimally. Research with the addition of variables and additional research samples in the future is recommended to be able to generalize the research results and obtain more valid data.

\section{REFERENCES}

Ali maksum. (2012). Metodologi Penelitian dalam Olahraga. Unesa University Press.

Brown, J. (2015). Tenis Lapangan Untuk Pemula (10th ed.). Rajagrafindo.

Chaturvedi, K., Vishwakarma, D. K., \& Singh, N. (2021). COVID-19 and its impact on education, social life and mental health of students: A survey. Children and Youth Services Review, 121(July 2020), 105866. https://doi.org/10.1016/j.childyouth.2020.105866

Cho, M.-J., \& Hong, J. P. (2021). The emergence of virtual education during the COVID-19 pandemic: The past, present, and future of the plastic surgery education. Journal of Plastic, Reconstructive \& Aesthetic Surgery, xxxx. https://doi.org/10.1016/j.bjps.2020.12.099

Corbett, F., \& Spinello, E. (2020). Connectivism and leadership: harnessing a learning theory for the digital age to redefine leadership in the twenty-first century. Heliyon, 6(1), e03250. https://doi.org/10.1016/j.heliyon.2020.e03250

Dian Pujianto, Asmawi, James Tangkudung, I. S. (2015). the Differences of Intructional Media and Coordination in Learning. Journal of Indonesian Physical Education and Sport (JIPES), 19-25. 
Differences Learning Outcomes At the forehand groundstrokes Beginner Athletes

Djalante, R., Lassa, J., Setiamarga, D., Sudjatma, A., Indrawan, M., Haryanto, B., Mahfud, C., Sabaruddin, M., Djalante, S., Ra, I., Adi, L., Ayu, G., Surtiari, K., \& Warsilah, H. (2020). Progress in Disaster Science Review and analysis of current responses to COVID-19 in Indonesia: Period of January to March 2020 is. 6. https://doi.org/10.1016/j.pdisas.2020.100091

Đorđić, V., Tubić, T., \& Jakšić, D. (2016). The Relationship between Physical, Motor, and Intellectual Development of Preschool Children. Procedia - Social and Behavioral Sciences, 233(May), 3-7. https://doi.org/10.1016/j.sbspro.2016.10.114

Elena, S., Georgeta, N., Cecila, G., \& Lupu, E. (2014). Perceptual-motor Development of Children in Elementary School. Procedia - Social and Behavioral Sciences, 114, 632636. https://doi.org/10.1016/j.sbspro.2013.12.759

Gatica-Rojas, V., Cartes-Velásquez, R., Guzmán-Muñoz, E., Méndez-Rebolledo, G., Soto-Poblete, A., Pacheco-Espinoza, A. C., Amigo-Mendoza, C., AlbornozVerdugo, M. E., \& Elgueta-Cancino, E. (2017). Effectiveness of a Nintendo Wii balance board exercise programme on standing balance of children with cerebral palsy: A randomised clinical trial protocol. Contemporary Clinical Trials Communications, 6, 17-21. https://doi.org/10.1016/j.conctc.2017.02.008

Pujianto, D. (2020). COMPETITOR : Jurnal Pendidikan Kepelatihan Olahraga Pemanfaatan Aplikasi Android Coach EYE Untuk. 12, 7-13.

Kolhar, M., Kazi, R. N. A., \& Alameen, A. (2021). Effect of social media use on learning, social interactions, and sleep duration among university students. Saudi Journal of Biological Sciences, xxxx. https://doi.org/10.1016/j.sjbs.2021.01.010

Meyer, O. A., Omdahl, M. K., \& Makransky, G. (2019). Investigating the effect of pretraining when learning through immersive virtual reality and video: A media and methods experiment. Computers and Education, 140(December 2018), 103603. https://doi.org/10.1016/j.compedu.2019.103603

Mishra, L., Gupta, T., \& Shree, A. (2020). Online teaching-learning in higher education during lockdown period of COVID-19 pandemic. International Journal of Educational Research Open, 1(June), 100012. https://doi.org/10.1016/j.ijedro.2020.100012

Munz, M., Baving, L., \& Prehn-Kristensen, A. (2021). Sleep following intense physical exercise stabilizes motor learning in typically developing boys. Mental Health and $\begin{array}{llll}\text { Physical Activity, 20(October } & & 200365),\end{array}$ https://doi.org/10.1016/j.mhpa.2020.100365

Samsudin. (2014). Media Pembelajaran Pendidikan Jasmani. Litera.

Seah, B., Ang, E. N. K., Liaw, S. Y., Lau, S. T., \& Wang, W. (2021). Curriculum changes for pre-registration nursing education in times of COVID-19: For the better or worse? Nurse Education Today, 98(November 2020). https://doi.org/10.1016/j.nedt.2020.104743

Siedentop, D. (1994). Introduction to Physical Education, Fitness, adn Sport (II). Mayfield Publishing Company. 
Differences Learning Outcomes At the forehand groundstrokes Beginner Athletes

Sukendro, S., Habibi, A., Khaeruddin, K., Indrayana, B., Syahruddin, S., Makadada, F. A., \& Hakim, H. (2020). Using an extended Technology Acceptance Model to understand students' use of e-learning during Covid-19: Indonesian sport science education $\quad$ Heliyon, $6(11), \quad$ e05410. https://doi.org/10.1016/j.heliyon.2020.e05410

Wingkel. (2017). Psikologi Pengajaran. Media Abadi. 